\title{
Projecting and Attributing Future Changes of Evaporative Demand over China in CMIP5 Climate Models $\mathscr{0}$
}

\author{
WENBIN LIU \\ Key Laboratory of Water Cycle and Related Land Surface Processes, Institute of Geographic Sciences and Natural \\ Resources Research, Chinese Academy of Sciences, Beijing, China \\ FUBAO SUN \\ Key Laboratory of Water Cycle and Related Land Surface Processes, Institute of Geographic Sciences and Natural \\ Resources Research, Chinese Academy of Sciences, and College of Resources and Environment, University of \\ Chinese Academy of Sciences, Beijing, and School of Civil Engineering, Hexi University, Zhangye City, China
}

(Manuscript received 25 August 2016, in final form 25 December 2016)

\begin{abstract}
Atmospheric evaporative demand plays a pivotal role in global water and energy budgets, and its change is very important for drought monitoring, irrigation scheduling, and water resource management under a changing environment. Here, future changes of pan evaporation $E_{\mathrm{pan}}$, a measurable indicator for atmospheric evaporative demand, are first projected and attributed over China through a physically based approach, namely, the PenPan model, forced with outputs from 12 state-of-the-art climate models from phase 5 of the Coupled Model Intercomparison Project. An equidistant quantile mapping method was also used to correct the biases in GCMs outputs to reduce uncertainty in $E_{\text {pan }}$ projection. The results indicated that $E_{\text {pan }}$ would increase during the periods 2021-50 and 2071-2100 relative to the baseline period 1971-2000 under the representative concentration pathway (RCP) 4.5 and 8.5 scenarios, which can mainly be attributed to the projected increase in air temperature and vapor pressure deficit over China. The percentage increase of $E_{\text {pan }}$ is relatively larger in eastern China than in western China, which is due to the spatially inconsistent increases in air temperature, net radiation, wind speed, and vapor pressure deficit over China. The widely reported "pan evaporation paradox" was not well reproduced for the period 1961-2000 in the climate models, before or after bias correction, suggesting discrepancy between observed and modeled trends. With that caveat, it was found that the pan evaporation has been projected to increase at a rate of $117-167 \mathrm{~mm} \mathrm{yr}^{-1} \mathrm{~K}^{-1}\left(72-80 \mathrm{~mm} \mathrm{yr}^{-1} \mathrm{~K}^{-1}\right)$ over China using the multiple GCMs under the RCP 4.5 (RCP 8.5) scenario with increased greenhouse gases and the associated warming of the climate system.
\end{abstract}

\section{Introduction}

As an important measure of atmospheric evaporative demand over terrestrial surface, pan evaporation $E_{\text {pan }}$ plays a critical role in hydrological applications such as lake evaporation estimation, irrigation scheduling, and drought monitoring (e.g., Shen et al. 2002; Roderick et al. 2007, 2009a,b; Wang et al. 2012, 2015; Berg et al. 2016). During the past half century, declines in $E_{\text {pan }}$ have been reported in many regions of the world and over a

Supplemental information related to this paper is available at the Journals Online website: http://dx.doi.org/10.1175/JHM-D-160204.s1.

Corresponding author e-mail: Fubao Sun, sunfb@igsnrr.ac.cn wide range of climates (e.g., Liu et al. 2004; Groisman et al. 2004; Roderick and Farquhar 2004, 2005; Tebakari et al. 2005; Burn and Hesch 2007; Zhang et al. 2007; Stanhill and Möller 2008; Fu et al. 2009), which are not in line with the expected more active hydrological cycle under a warmer climate associated with the anthropogenic greenhouse effects from climate models (e.g., Rotstayn et al. 2006; Dai 2006).

The long-term controversy on how the atmospheric evaporative demand would change is commonly known as the "pan evaporation paradox," which was confirmed worldwide and has been interpreted from various aspects (e.g., a moistening of the air, anthropogenic aerosol-induced solar diming, and the weakening wind speed) of hydrology and climate sciences over different regions (e.g., Brutsaert and Parlange 1998; Peterson 
et al. 1995; Roderick and Farquhar 2002; Liepert et al. 2004; Hobbins et al. 2004; Roderick et al. 2007; McVicar et al. 2012). In China, it has been reported that $E_{\mathrm{pan}}$ extensively decreased over the period 1955-2007 due to the decreased wind speed and solar radiation (e.g., Liu et al. 2004; Chen et al. 2005; Liu et al. 2011; Li et al. 2013; Wang et al. 2015). However, there are still some questions that remain unknown, such as 1 ) whether $E_{\mathrm{pan}}$ over China would continue to decline in the future under different greenhouse emission scenarios, and 2) which climatic variable contributes to the projected changes of Chinese $E_{\mathrm{pan}}$ ? Answers to these questions are critical for understanding the water and energy budgets under a changing climate and will benefit us for water resource management and drought prediction in China.

The mass and energy balances of pan evaporation can be described by a modified Penman equation (e.g., Penman 1948), namely, the PenPan model (e.g., Rotstayn et al. 2006), which coupled the radiative component of Linacre (1994) with the aerodynamic component developed by Thom et al. (1981). During the past several years, it has successfully been used in estimating and attributing the observed changes of $E_{\mathrm{pan}}$ at site or regional scales in the United States (e.g., Hobbins et al. 2012), Australia (e.g., Roderick et al. 2007), Spain (e.g., AzorinMolina et al. 2015), and China (e.g., Li et al. 2013; Wang et al. 2015), among others. The well-calibrated PenPan model has also been forced by global climate model (GCM) outputs to assess the performance of GCM in estimating the atmospheric evaporative demand against the observed $E_{\text {pan }}$ (e.g., Rotstayn et al. 2006). However, the application of GCM outputs to regional (or site) scale is often restricted by their coarse resolutions and limited capabilities in resolving key regional factors such as topography, clouds, and land use (e.g., Fowler et al. 2007; Maraun et al. 2010). Moreover, the GCM-estimated $E_{\mathrm{pan}}$ has considerable uncertainty inherited from the biased GCM outputs for regional applications (e.g., Liu and Sun 2016). The gaps between the GCM outputs and regional hydrological applications can be bridged through the downscaling techniques (e.g., Liu et al. 2013, 2015; Wang et al. 2013). Compared with dynamical downscaling, statistical downscaling is more widely applied in hydrological studies because of its relatively lower computing resource requirements and the ability to incorporate observations into the method (e.g., Wilks 2012; Ye et al. 2012; Vautard et al. 2014).

The objective of this study is to project the future changes of Chinese $D_{20}$ pan evaporation (measured by a metal micropan with $20 \mathrm{~cm}$ in diameter and $10 \mathrm{~cm}$ in depth on a wooden platform at $70 \mathrm{~cm}$ height above the ground) using the PenPan model driven by a suite of latest climate models from phase 5 of the Coupled Model
Intercomparison Project (CMIP5) under two emission scenarios [representative concentration pathway (RCP) 4.5 and RCP 8.5]. The contributions of surface air temperature, vapor pressure deficit, net radiation, and wind speed to the changes of future $E_{\mathrm{pan}}$ are also investigated for the periods 2021-50 and 2071-2100. The results would provide valuable insight into the changes of water and energy cycles and would thus be helpful for water resource regulation and agricultural water management over China in a warmer world.

\section{Data and methods}

\section{a. Observational and climate model data}

In this study, we used the observed daily mean, minimum, and maximum air temperature; wind speed; air pressure; relative humidity; sunshine duration; and $D_{20}$ pan evaporation; which were obtained from the China Meteorological Data Service Center (http://data.cma. $\mathrm{cn} / \mathrm{en}$ ) and have been carefully quality controlled before being released to the scientific community. A total of 534 out of 756 stations with continuing measurement over the period 1961-2000 were finally chosen to ensure the overall statistics were robust (Fig. 1). The monthly outputs (including mean, minimum, and maximum surface air temperature; surface air pressure; relative humidity; surface zonal velocity component and meridional velocity component; surface downwelling longwave flux; surface downwelling shortwave flux; and incident shortwave radiation at the top of the atmosphere) from 12 CMIP5 GCMs (detailed information for these models are listed in Table 1 and can also be found at the IPCC Data Distribution Centre website: http:// ipcc-ddc.cru.uea.ac.uk) archived at the Program for Climate Model Diagnosis and Intercomparison website (https://pcmdi.llnl.gov/projects/esgf-llnl/) were also applied. Historical (1961-2000) and future simulations (2021-50 and 2071-2100) of 12 GCMs under two emission scenarios (RCP 4.5 and RCP 8.5) were used to drive the PenPan model after bias correction. Moreover, all GCM climate fields were regridded to a uniform $1^{\circ} \times 1^{\circ}$ resolution through bilinear interpolation since the horizontal resolution varies between different GCMs.

\section{b. EQM method}

The GCM outputs usually have considerable systematic errors (biases) that constrain their applications at regional or site scale. Statistical downscaling (including the empirical downscaling) is widely used to bias-correct GCM outputs and downscale them to a finer spatial resolution. The quantile mapping $(\mathrm{QM})$ method is a relatively simple and straightforward empirical downscaling approach, which has been widely applied in 


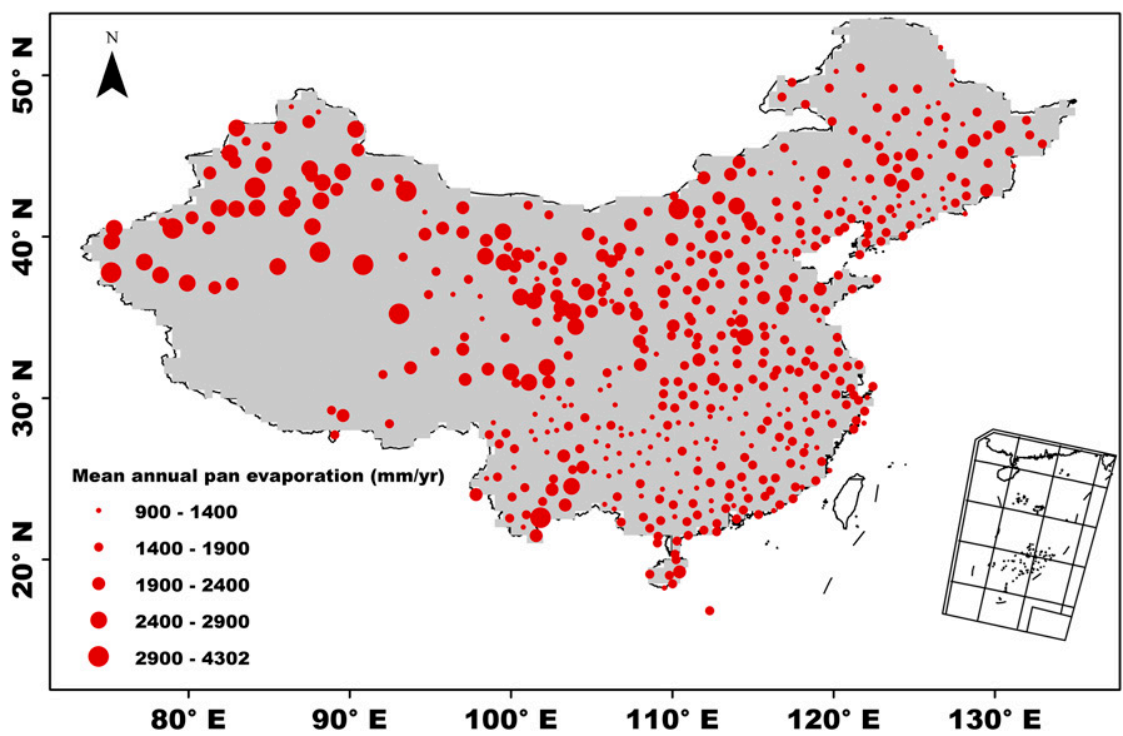

FIG. 1. Locations of the meteorological stations over China. The multiyear (1961-2000) means of observed annual $E_{\mathrm{pan}}\left(D_{20}\right.$ pan $)$ are also shown at 534 stations used in this study.

many climate impact studies (e.g., Maurer and Hidalgo 2008; Wilcke et al. 2013). For a certain climate variable $X$, the distribution of GCM output $X$ can be mapped onto that of observed $X$ (e.g., Panofsky and Brier 1968):

$$
X_{m_{p}, \text { bias corrected }}=F_{o_{c}}^{-1}\left[F_{m_{c}}\left(X_{m_{p}}\right)\right],
$$

where $F$ is the cumulative distribution function $(\mathrm{CDF})$ of either the observations $o$ or model $m$ for current $c$ or projected $p$ climate. The underlying assumption of $\mathrm{QM}$ is that the climate distribution does not change much over time. However, it may not hold with the possibility that the GCM projection changes in higher moments as well (e.g., Milly et al. 2008; Van Schaeybroeck and Vannitsem 2016). Li et al. (2010) proposed a revised version of QM [equidistant quantile mapping (EQM)] by adjusting the model CDF in the projection period through the difference between the observation and model CDFs for the baseline (historical) period (Fig. 2), which explicitly considers the changes of probability distribution (e.g., the tails of the distribution) for a given model between the

TABLE 1. Properties of CMIP5 climate models used in this study.

\begin{tabular}{|c|c|c|c|}
\hline Model name & Abbreviation & Modeling center & $\begin{array}{l}\text { Atmospheric resolution } \\
\quad(\text { lat } \times \text { lon })\end{array}$ \\
\hline ACCESS1.0 & ACCESS & $\begin{array}{l}\text { Commonwealth Scientific and Industrial Research Organisation/Bureau of } \\
\text { Meteorology (Australia) }\end{array}$ & $1.300^{\circ} \times 1.900^{\circ}$ \\
\hline BCC_CSM1.1 & $\mathrm{BCC}$ & Beijing Climate Center (China) & $2.813^{\circ} \times 2.791^{\circ}$ \\
\hline BNU-ESM & BNU & Beijing Normal University (China) & $2.810^{\circ} \times 2.810^{\circ}$ \\
\hline CanESM2 & CanESM & Canadian Centre for Climate Modelling and Analysis (Canada) & $2.813^{\circ} \times 2.791^{\circ}$ \\
\hline CNRM-CM5 & CNRM & $\begin{array}{l}\text { Centre National de Recherches Météorologiques/Centre Européen de } \\
\text { Recherche et de Formation Avancée en Calcul Scientifique (France) }\end{array}$ & $1.406^{\circ} \times 1.401^{\circ}$ \\
\hline CSIRO Mk3.6.0 & CSIRO & $\begin{array}{l}\text { Commonwealth Scientific and Industrial Research Organisation/ } \\
\text { Queensland Climate Change Centre of Excellence (Australia) }\end{array}$ & $1.875^{\circ} \times 1.866^{\circ}$ \\
\hline GFDL CM3 & GFDL & Geophysical Fluid Dynamics Laboratory (United States) & $2.500^{\circ} \times 2.000^{\circ}$ \\
\hline HadGEM2-AO & HadGEM & $\begin{array}{l}\text { National Institute of Meteorological Research/Korea Meteorological } \\
\text { Administration (South Korea) }\end{array}$ & $1.300^{\circ} \times 1.900^{\circ}$ \\
\hline INM-CM4.0 & INM & Russian Academy of Sciences/Institute of Numerical Mathematics (Russia) & $2.000^{\circ} \times 1.500^{\circ}$ \\
\hline IPSL-CM5B-LR & IPSL & L'Institut Pierre-Simon Laplace (France) & $1.875^{\circ} \times 3.750^{\circ}$ \\
\hline MRI-CGCM3 & MRI & Meteorological Research Institute (Japan) & $1.125^{\circ} \times 1.125^{\circ}$ \\
\hline MIROC-ESM & MIROC & $\begin{array}{l}\text { Atmosphere and Ocean Research Institute (University of Tokyo)/National } \\
\text { Institute for Environmental Studies/Japan Agency for Marine-Earth } \\
\text { Science and Technology (Japan) }\end{array}$ & $2.813^{\circ} \times 2.791^{\circ}$ \\
\hline Ensemble mean & EM & - & - \\
\hline
\end{tabular}




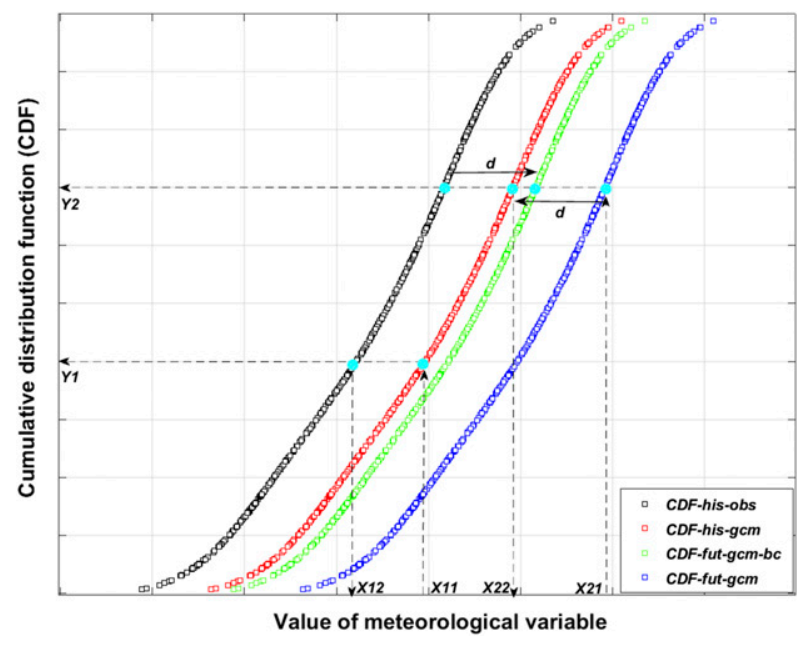

FIG. 2. Schematic diagram for the EQM method. The $X_{11}, X_{12}$, $X_{21}$, and $X_{22}$ are values of certain meteorological variables (i.e., air temperature, air pressure, and net radiation), and $Y_{1}$ and $Y_{2}$ are their corresponding cumulative probabilities. CDF-his-obs and CDF-his-gcm show the CDFs of observed (i.e., $X_{12}$ ) and GCMoutputted (i.e., $X_{11}$ ) historical data while CDF-fut-gcm and CDFfut-gcm-bc represent the CDFs of GCM-projected future data (i.e., $\left.X_{21}\right)$ and its bias-corrected data.

baseline and projection periods. It can be written mathematically as

$$
X_{m_{p}, \text { bias corrected }}=X_{m_{p}}+F_{o_{c}}^{-1}\left[F_{m_{p}}\left(X_{m_{p}}\right)\right]-F_{m_{c}}^{-1}\left[F_{m_{p}}\left(X_{m_{p}}\right)\right] .
$$

Currently, the EQM method has been successfully applied in various climate-impact-oriented applications (e.g., Li et al. 2010; Srivastav et al. 2014). Readers can also refer to Sachindra et al. (2014) for more details about the EQM method.

In this study, the EQM method was applied to all input variables for the PenPan model, including the monthly minimum temperature, maximum temperature, relatively humidity, wind speed at $2 \mathrm{~m}$, vapor pressure deficit, and net radiation. For each GCM output, an EQM-based bias correction was conducted for every grid with site observations by matching the CDFs of observed and modeled monthly series. The obtained time series was taken as the bias-corrected GCM simulation for the site used. We then repeated the above procedure for all 534 sites over China and for both historical [Eq. (1)] and future [Eq. (2)] time periods. Li et al. (2010) suggested that a suitable theoretical distribution function might be fitted prior to the application of the EQM method to minimize the overprediction of the maxima of certain variables due to the extrapolation of the CDF. However, it is very difficult to choose a suitable theoretical distribution for each variable when we conduct the EQM method for multivariable applications and there are still considerable fitting errors when a theoretical distribution function is applied to a dataset. The empirical distribution function can also describe any variable and dataset perfectly (e.g., Sachindra et al. 2014). Thus, in this study, the empirical CDF was used in the EQM method for each meteorological variable and each climate model for the future (2021-50 and 2071-2100) and historical (1961-2000) periods.

\section{c. The PenPan model}

By assuming a steady-state energy balance, $E_{\mathrm{pan}}$ can be calculated as the sum of the aerodynamic $E_{p_{A}}\left(\mathrm{~kg} \mathrm{~m}^{-2} \mathrm{~s}^{-1}\right)$ and radiative $E_{p_{R}}\left(\mathrm{~kg} \mathrm{~m}^{-2} \mathrm{~s}^{-1}\right)$ components in the PenPan model (e.g., Rotstayn et al. 2006; Roderick et al. 2009a; Lim et al. 2013) on a monthly basis,

$$
E_{\mathrm{pan}}=E_{p_{R}}+E_{p_{A}}=\left(\frac{\Delta}{\Delta+a \gamma} \frac{R_{n}}{\lambda}\right)+\left[\frac{a \gamma}{\Delta+a \gamma} f_{q}(u) D\right],
$$

where $\lambda$ is the latent heat of vaporization $\left(2.45 \times 10^{6} \mathrm{~J} \mathrm{Kg}^{-1}\right)$; $a$ is the ratio of effective surface areas for vapor and heat transfer calculated based on the pan size ( 4.2 for the $D_{20}$ pan; e.g., Li et al. 2013); $\Delta\left(\mathrm{Pa} \mathrm{K}^{-1}\right)$ is the slope of the change in saturation vapor pressure $e_{s}(\mathrm{~Pa})$ estimated at the air temperature $T_{a}(\mathrm{~K}) 2 \mathrm{~m}$ above the ground; $\gamma$ is the psychrometric constant $\left(\approx 67 \mathrm{~Pa} \mathrm{~K}^{-1}\right)$, which can also be calculated based on the surface air pressure at $2 \mathrm{~m}$ above the ground $(\mathrm{Pa}) ; D$ is the vapor pressure deficit $\left(e_{s}-e_{a} ; \mathrm{Pa}\right)$ estimated using the actual vapor pressure $e_{a}(\mathrm{~Pa})$ and saturation vapor pressure, which is evaluated at $T_{a} ; R_{n}$ is the net radiation of the pan; and $f_{q}(u)$ is the empirical vapor transfer function. Moreover, Roderick et al. (2007) proposed an approach in attributing $E_{\text {pan }}$ changes to different meteorological forcing based on the PenPan model:

$$
\frac{d E_{\mathrm{pan}}}{d t}=\frac{\partial E_{\mathrm{pan}}}{\partial T_{a}} \frac{d T_{a}}{d t}+\frac{\partial E_{\mathrm{pan}}}{\partial u_{2}} \frac{d u_{2}}{d t}+\frac{\partial E_{\mathrm{pan}}}{\partial D} \frac{d D}{d t}+\frac{\partial E_{\mathrm{pan}}}{\partial R_{n}} \frac{d R_{n}}{d t}
$$

Based on Eq. (4), the contribution of $T_{a}, R_{n}, D$, and wind speed at $2 \mathrm{~m} u_{2}$ to $E_{\text {pan }}$ changes $\left(d E_{\mathrm{pan}} / d t\right)$ can be obtained by calculating the partial derivatives multiplied by the trends (e.g., $d T_{a} / d t, d u_{2} / d t, d D / d t$, and $d R_{n} / d t$ for the changes of $T_{a}, u_{2}, D$, and $R_{n}$, respectively) at annual, seasonal, and monthly time scales. The term $t$ represents the time. For more details about the estimation of each parameter in Eq. (3) and the expansion formulas of $\partial E_{\mathrm{pan}} / \partial T_{a}, \partial E_{\mathrm{pan}} / \partial u_{2}, \partial E_{\mathrm{pan}} / \partial D$, and $\partial E_{\mathrm{pan}} / \partial R_{n}$ in Eq. (4), 
(a)

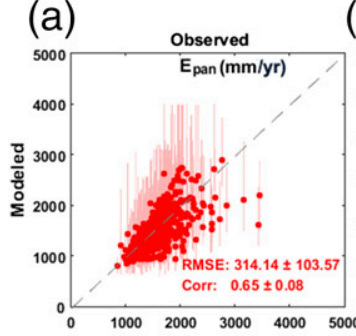

(b)

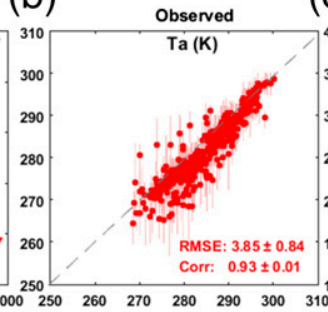

(c)

(g)

(h)

(d)

(e) observed
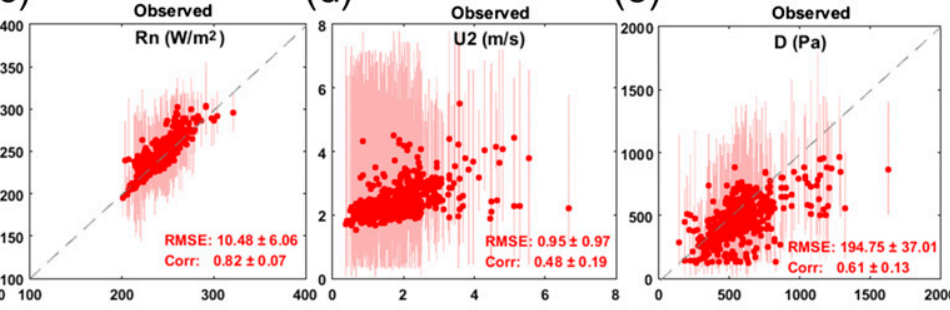

(i)

(j)
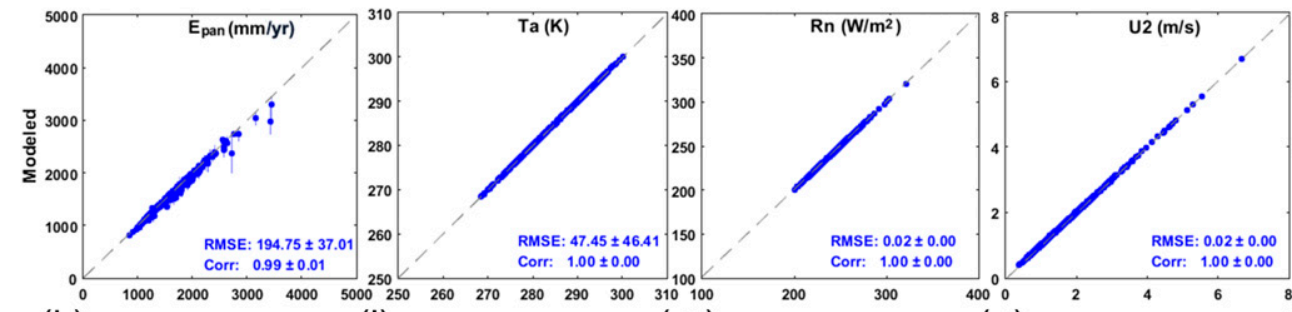

(I)

(m)

(n)

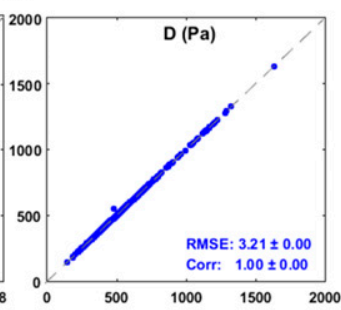

(k)

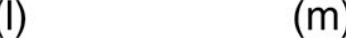

(o)
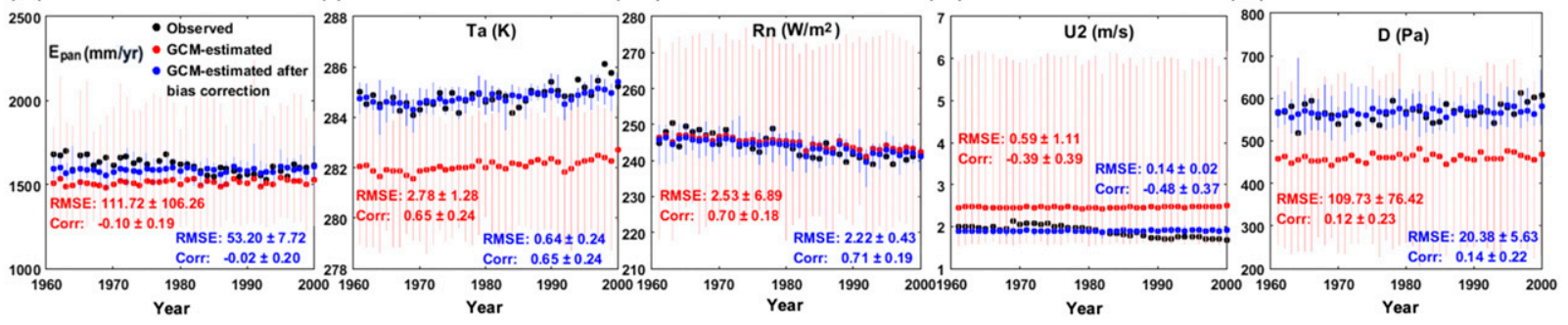

FIG. 3. Validation of the EQM method for GCM-estimated annual $T_{a}, R_{n}, u_{2}$, and $D$ (and thus the calculated $E_{\text {pan }}$ ) over China during the period 1961-2000. Uncertainties (minimum-maximum ranges) from multiple climate models are exhibited for estimations with the original (light red vertical lines) and bias-corrected (light blue vertical lines) GCM outputs, respectively. (a),(b),(f),(g),(k),(l) The multimodel ensemble means of each variable at 534 stations before (red dots) and after (blue dots) bias correction. The multisite averages (plus/minus std devs) of RMSE and Corr between the observed and modeled (multimodel ensemble mean) multiyear means of each variable at 534 stations before (red fonts) and after (blue fonts) correction are also shown. (c),(h),(m) The interannual variability of observation (black dots) as well as multisite-averaged multimodel ensemble mean for each variable. It should be noted that the RMSEs and Corrs in (c),(h),(m) show the RMSEs and correlation coefficients between multisite-averaged annual series of observation and multimodel ensemble mean for each variable.

please refer to the appendix as well as other related studies (e.g., Roderick et al. 2007; Hobbins et al. 2012; Li et al. 2013; Wang et al. 2015; Liu and Sun 2016).

\section{Results and discussion}

\section{a. Performances of the EQM method on individual climate variables and the estimated $E_{\mathrm{pan}}$}

The performances of $12 \mathrm{GCMs}$ in estimating $E_{\mathrm{pan}}$ were evaluated against the $D_{20}$ pan observations over China during the period 1961-2000 in our previous study (e.g., Liu and Sun 2016). Considerable uncertainties were found in GCM-estimated $E_{\mathrm{pan}}$ due to the biased GCM outputs (e.g., air temperature, vapor pressure deficit, net radiation, and wind speed) used in $E_{\text {pan }}$ calculation. The biased results cannot be directly used for projecting the future changes of $E_{\text {pan }}$. Therefore, in this study, we first correct the coarse GCM outputs using the EQM method and then apply them to the future projection of $E_{\text {pan }}$ over China.

The performances of the EQM method in bias correcting the annual $T_{a}, R_{n}, u_{2}$, and $D$ (and thus the estimated $\left.E_{\text {pan }}\right)$ were first evaluated over the period 1961-2000 for 12 climate models and for 534 meteorological stations over China (Fig. 3, Table 2). It showed that the EQM method significantly corrected the multiyear means of $T_{a}, R_{n}, u_{2}$, and $D$ for all climate models (and thus for the multimodel ensemble mean) and for all stations. For example, the root-mean-square error (RMSE) between the observed and modeled multiyear means of $R_{n}$ at 534 stations obviously decrease (from around $10.48 \pm 6.06$ to $0.02 \pm 0.00 \mathrm{~W} \mathrm{~m}^{-2}$ ) while their correlation coefficient (Corr) markedly increase (from around $0.82 \pm 0.07$ to $1.00 \pm 0.00$ ) after bias correction (Fig. 3). Moreover, the standard deviations (std dev) of 
TABLE 2. Multisite-averaged statistics (avg and std dev) of observed and GCM-estimated annual $T_{a}, R_{n}, D$, and $u_{2}$ (and thus the calculated $\left.E_{\text {pan }}\right)$ over China before (Original) and after bias correction (BC) during the period 1961-2000.

\begin{tabular}{|c|c|c|c|c|c|c|c|c|c|c|c|c|c|c|}
\hline \multicolumn{2}{|l|}{ Statistics } & Obs & ACCESS & $\mathrm{BCC}$ & $\mathrm{BNU}$ & CanESM & I CNRM & CSIRO & GFDL & HadGEM & INM & IPSL & MRI & MIROC \\
\hline \multicolumn{15}{|l|}{$E_{\text {pan }}(\mathrm{mm})$} \\
\hline \multirow[t]{2}{*}{ Avg } & Original & 1612.50 & 1288.90 & 1983.50 & 1461.90 & 1493.30 & 1444.60 & 1584.30 & 1314.80 & 1383.40 & 1270.60 & 1733.70 & 1680.80 & 1499.90 \\
\hline & $\mathrm{BC}$ & & 1603.10 & 1615.90 & 1572.40 & 1593.10 & 1593.00 & 1569.20 & 1588.30 & 1570.90 & 1584.70 & 1583.30 & 1588.10 & 1568.10 \\
\hline \multirow[t]{2}{*}{ Std dev } & Original & 112.97 & 97.00 & 195.81 & 107.10 & 99.23 & 101.82 & 100.43 & 95.57 & 97.14 & 71.84 & 93.07 & 86.60 & 104.05 \\
\hline & $\mathrm{BC}$ & & 105.03 & 97.91 & 87.17 & 97.96 & 95.32 & 78.54 & 109.28 & 89.77 & 82.93 & 86.06 & 74.57 & 105.45 \\
\hline \multicolumn{15}{|l|}{$T_{a}(\mathrm{~K})$} \\
\hline \multirow[t]{2}{*}{ Avg } & Original & 284.83 & 282.46 & 281.76 & 282.40 & 283.58 & 281.88 & 282.32 & 281.44 & 282.71 & 279.20 & 280.69 & 282.09 & 284.29 \\
\hline & $\mathrm{BC}$ & & 284.78 & 284.78 & 284.78 & 284.78 & 284.78 & 284.78 & 284.78 & 284.78 & 284.78 & 284.78 & 284.78 & 284.78 \\
\hline \multirow[t]{2}{*}{ Std dev } & Original & 0.60 & 0.62 & 0.61 & 0.77 & 0.70 & 0.63 & 0.54 & 0.69 & 0.71 & 0.64 & 0.75 & 0.51 & 0.62 \\
\hline & $\mathrm{BC}$ & & 0.58 & 0.58 & 0.69 & 0.67 & 0.60 & 0.52 & 0.66 & 0.59 & 0.59 & 0.66 & 0.49 & 0.65 \\
\hline \multicolumn{15}{|c|}{$R_{n}\left(\mathrm{~W} \mathrm{~m}^{-2}\right)$} \\
\hline \multirow[t]{2}{*}{ Avg } & Original & 243.82 & 231.21 & 222.89 & 36.30 & & & 252.68 & & & & & & 258.60 \\
\hline & $\mathrm{BC}$ & & 243.82 & 243.82 & 243.82 & 243.82 & 243.82 & 243.82 & 243.82 & 243.82 & 243.82 & 243.82 & 243.82 & 243.82 \\
\hline \multirow[t]{2}{*}{ Std dev } & Original & 6.61 & 7.26 & 7.13 & 6.02 & 6.91 & 5.40 & 5.04 & 5.85 & 6.00 & 4.63 & 5.64 & 4.41 & 5.61 \\
\hline & $\mathrm{BC}$ & & 7.52 & 7.28 & 6.10 & 7.42 & 6.80 & 5.37 & 6.94 & 6.38 & 5.30 & 5.58 & 4.82 & 6.00 \\
\hline \multicolumn{15}{|l|}{$D(\mathrm{~Pa})$} \\
\hline \multirow[t]{2}{*}{ Avg } & Original & 568.14 & 404.22 & 410.46 & 401.30 & 375.42 & 491.19 & 552.03 & 404.36 & 497.29 & 249.47 & 632.62 & 625.92 & 480.43 \\
\hline & $\mathrm{BC}$ & & 568.14 & 568.28 & 568.28 & 568.28 & 568.28 & 568.28 & 568.28 & 568.28 & 568.28 & 568.28 & 568.28 & 568.28 \\
\hline \multirow[t]{2}{*}{ Std dev } & Original & 53.46 & 56.19 & 59.69 & 51.41 & 46.73 & 67.56 & 81.68 & 64.33 & 72.40 & 40.51 & 58.57 & 60.24 & 80.26 \\
\hline & $\mathrm{BC}$ & & 51.86 & 52.36 & 46.52 & 56.84 & 58.21 & 57.57 & 66.19 & 52.45 & 51.86 & 53.62 & 46.48 & 72.38 \\
\hline \multicolumn{15}{|c|}{$u_{2}\left(\mathrm{~m} \mathrm{~s}^{-1}\right)$} \\
\hline \multirow[t]{2}{*}{ Avg } & Original & 1.89 & 1.69 & 6.01 & 2.74 & 2.91 & 2.05 & 2.34 & 1.78 & 1.60 & 2.17 & 2.17 & 2.11 & 1.94 \\
\hline & $\mathrm{BC}$ & & 1.89 & 1.90 & 1.90 & 1.9 & 1.9 & 1.90 & 1.90 & 1.90 & 1.9 & 1.90 & 1.90 & 1.90 \\
\hline \multirow[t]{2}{*}{ Std dev } & Original & 0.26 & 0.07 & 0.15 & 0.11 & 0.13 & 0.09 & 0.10 & 0.07 & 0.07 & 0.09 & 0.10 & 0.10 & 0.16 \\
\hline & $\mathrm{BC}$ & & 0.12 & 0.09 & 0.12 & 0.11 & 0.11 & 0.09 & 0.12 & 0.11 & 0.10 & 0.12 & 0.12 & 0.13 \\
\hline
\end{tabular}

annual $T_{a}, R_{n}, D$, and $u_{2}$ calculated from the biascorrected GCM outputs are closer to those computed from the observations for most climate models (e.g., 8 out of 12 models, namely, the BNU, CNRM, CSIRO, GFDL, HadGEM, INM, MRI, and MIROC models for annual $R_{n}$; Table 2). The RMSE (Corr) between the observed and GCM-calculated (after bias correction) annual $E_{\text {pan }}$ was also reduced (enhanced) from $314.14 \pm$ $103.57 \mathrm{~mm} \mathrm{yr}^{-1}(0.65 \pm 0.06)$ to $194.75 \pm 37.01 \mathrm{~mm} \mathrm{yr}^{-1}$ $(0.99 \pm 0.01)$. The uncertainties among multiple GCMs were significantly narrowed (for either the multiyear means or the annual means) after correction. Similar results were also exhibited in seasonal $E_{\text {pan }}$ (Fig. 4, Table 3). The results were in agreement with those found by $\mathrm{Li}$ et al. (2010) and Sachindra et al. (2014), which revealed the effectiveness of the EQM method in correcting the coarse GCM outputs and for multivariable applications.

It should be noted that the interannual variability (revealed by the standard deviation) of multisiteaveraged multimodel ensemble means of each variable (i.e., $T_{a}, R_{n}, u_{2}, D$, and $E_{\mathrm{pan}}$ ) after bias correction was still similar to that calculated from the original GCM outputs (Figs. 3, 4), which revealed the limited ability of QM-type bias correction techniques in correcting the GCM-simulated climate variability (e.g., Sachindra et al. 2014). It can thus explain the unimproved (or not significantly improved) correlation coefficients between the multisite-averaged annual series of observed and modeled (multimodel ensemble mean) $E_{\mathrm{pan}}$ (and for other variables such as $T_{a}, R_{n}, D$, and $u_{2}$ ) after bias correction (Figs. 3, 4). However, the absolute value of each variable matched significantly with the observation after bias correction. We thus focused only on the absolute changes of multiyear means for $E_{\mathrm{pan}}, T_{a}, R_{n}, u_{2}$, and $D$ in future periods (2021-50 and 2071-2100) in this study, relative to that during the baseline period 19712000 , considering the limitation of EQM-based bias correction.

\section{b. Future changes of Chinese $E_{\text {pan }}$}

Here we projected the future changes of Chinese $E_{\text {pan }}$ for the periods $2021-50$ and $2071-2100$, relative to that during the baseline period 1971-2000, based on multiple GCMs under two emission scenarios (RCP 4.5 and RCP 8.5; Fig. 5). Averaged over all sites, the projected increase in the median of multimodel-estimated annual $E_{\mathrm{pan}}$ is $123 \mathrm{~mm} \mathrm{yr}^{-1}$ (range is $12-310 \mathrm{~mm} \mathrm{yr}^{-1}$ ) for RCP 4.5 and $114 \mathrm{~mm} \mathrm{yr}^{-1}$ (range is $48-209 \mathrm{~mm} \mathrm{yr}^{-1}$ ) for RCP 8.5 during the period $2021-50$ relative to $1971-2000$. It is in agreement with the projections of reference evaporation calculated using the Food and Agriculture Organization of the United Nations (FAO) 56 PenmanMonteith method at both the national (e.g., Yin et al. 2015) and regional (e.g., $\mathrm{Xu}$ et al. 2014) scales over 

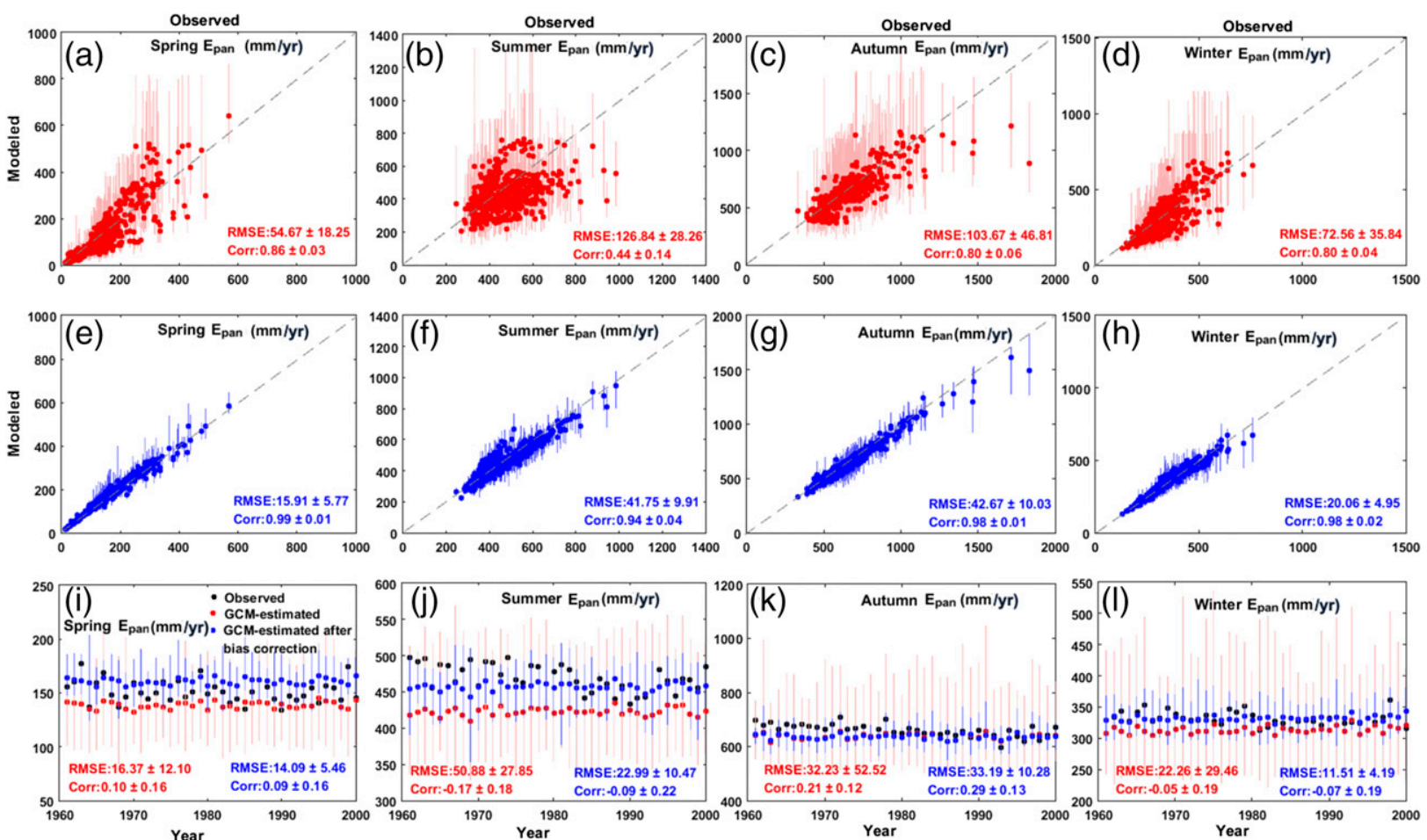

FIG. 4. As in Fig. 3, but for GCM-estimated seasonal $E_{\text {pan }}$.

China. Correspondingly, averaged over all sites, the projected increase in the medians of multimodelsimulated $T_{a}, u_{2}$, and $D$ are $1.5^{\circ} \mathrm{C}$ (range is $0.9^{\circ}-2.5^{\circ} \mathrm{C}$ ), $0.01 \mathrm{~m} \mathrm{~s}^{-1}$ (range is from -0.04 to $0.14 \mathrm{~m} \mathrm{~s}^{-1}$ ), and $60 \mathrm{~Pa}$ (range is 2-230 Pa), respectively, under RCP 4.5 and are $1.7^{\circ} \mathrm{C}$ (range is $1.0^{\circ}-2.2^{\circ} \mathrm{C}$ ), $0.01 \mathrm{~m} \mathrm{~s}^{-1}$ (range is from -0.03 to $0.12 \mathrm{~m} \mathrm{~s}^{-1}$ ), and $64 \mathrm{~Pa}$ (range is $19-158 \mathrm{~Pa}$ ) under RCP 8.5 for the period 2021-50 relative to the baseline period. For the period 2071-2100, the annual $E_{\mathrm{pan}}, T_{a}, R_{n}$, and $D$ would significantly increase over

TABLE 3. Multisite-averaged statistics (avg and std dev) of observed and GCM-estimated seasonal $T_{a}, R_{n}, D$, and $u_{2}$ (and thus the calculated $E_{\text {pan }}$ ) over China before (Original) and after bias correction (BC) over the period 1961-2000.

\begin{tabular}{cllrrrrrrrrrrrrr}
\hline \hline Statistics & & Obs & ACCESS & BCC & BNU & CanESM & CNRM & CSIRO & GFDL & HadGEM & INM & IPSL & MRI & MIROC \\
\hline Spring & & & & & & & & & & & & & & & \\
Avg & Original & 151.30 & 108.35 & 178.66 & 119.94 & 161.97 & 130.35 & 164.84 & 128.17 & 110.34 & 102.89 & 160.93 & 146.14 & 151.64 \\
& BC & & 154.14 & 148.64 & 158.26 & 172.09 & 156.41 & 169.24 & 165.60 & 152.97 & 164.62 & 156.80 & 156.96 & 173.44 \\
Std dev & Original & 20.85 & 12.17 & 31.35 & 21.76 & 19.65 & 17.17 & 19.95 & 20.63 & 16.73 & 13.43 & 24.04 & 13.11 & 19.35 \\
& BC & & 17.98 & 18.10 & 23.15 & 22.42 & 20.01 & 20.53 & 25.48 & 19.96 & 24.30 & 18.36 & 15.42 & 24.07 \\
Summer & & & & & & & & & & & & & \\
Avg & Original & 469.70 & 363.71 & 491.72 & 387.56 & 430.96 & 411.71 & 435.38 & 370.32 & 389.70 & 368.81 & 523.83 & 469.84 & 430.36 \\
& BC & & 463.15 & 423.99 & 430.80 & 474.29 & 468.12 & 442.25 & 460.46 & 455.19 & 471.53 & 473.77 & 460.62 & 462.43 \\
Std dev & Original & 47.43 & 41.74 & 86.38 & 58.60 & 46.48 & 44.71 & 43.39 & 41.67 & 42.68 & 39.02 & 49.04 & 40.77 & 40.62 \\
& BC & & 48.21 & 46.08 & 49.72 & 46.69 & 45.82 & 36.97 & 51.44 & 42.31 & 44.80 & 45.87 & 36.09 & 43.77 \\
Autumn & & & & & & & & & & & & & \\
Avg & Original & 659.89 & 557.61 & 864.55 & 655.17 & 584.74 & 602.36 & 646.08 & 528.36 & 602.46 & 556.40 & 673.95 & 737.95 & 635.84 \\
& BC & & 649.71 & 692.42 & 654.04 & 607.70 & 634.79 & 616.66 & 619.02 & 638.25 & 630.65 & 616.10 & 651.65 & 623.72 \\
Std dev & Original & 59.99 & 65.64 & 129.14 & 65.81 & 59.46 & 61.33 & 59.33 & 50.74 & 61.65 & 41.69 & 51.16 & 53.92 & 63.50 \\
& BC & & 66.61 & 63.69 & 52.25 & 58.54 & 54.28 & 44.61 & 58.07 & 53.79 & 45.66 & 48.64 & 45.20 & 60.85 \\
Winter & & & & & & & & & & & & \\
Avg & Original & 331.65 & 259.25 & 448.55 & 299.26 & 315.66 & 300.14 & 337.96 & 287.99 & 280.88 & 242.52 & 375.01 & 326.8 & 282.08 \\
& BC & & 336.08 & 350.80 & 329.26 & 339.04 & 333.64 & 341.08 & 343.20 & 324.52 & 317.90 & 336.58 & 318.915 & 308.50 \\
Std dev & Original & 32.96 & 29.11 & 77.69 & 39.33 & 34.81 & 35.46 & 41.04 & 34.32 & 31.24 & 21.67 & 35.39 & 31.84 & 28.33 \\
& BC & & 36.85 & 40.37 & 33.45 & 36.82 & 34.21 & 33.15 & 38.91 & 32.84 & 30.26 & 33.16 & 27.99 & 32.11 \\
\hline
\end{tabular}



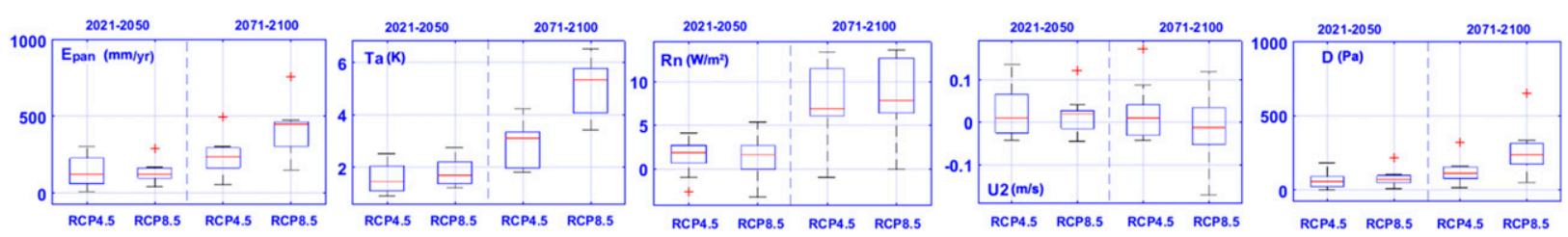

FIG. 5. Changes of multisite-averaged annual $E_{\mathrm{pan}}, T_{a}, R_{n}, u_{2}$, and $D$ over China during the periods 2021-50 and 2071-2100 under the RCP 4.5 and RCP 8.5 scenarios, relative to that during the baseline period 1971-2000. The projected uncertainty of multiple climate models is shown through box plots for each variable and for each time period. The outliers are shown with red crosses.

China relative to 1971-2000, especially under the RCP 8.5 scenario. For example, the projected increase in the median of multimodel-estimated annual $E_{\text {pan }}$ is $240 \mathrm{~mm} \mathrm{yr}^{-1}$ (range is $59-498 \mathrm{~mm} \mathrm{yr}^{-1}$ ) for RCP 4.5 and $414 \mathrm{~mm} \mathrm{yr}^{-1}$ (range is $161-653 \mathrm{~mm} \mathrm{yr}^{-1}$ ) under RCP 8.5. However, the net radiation would not obviously increase but would decrease under RCP 8.5 (median is $0.5 \mathrm{~W} \mathrm{~m}^{-2}$ and range is from -2.5 to $4.5 \mathrm{~W} \mathrm{~m}^{-2}$ during the period 2021-50) relative to that under RCP 4.5 (median is $1.9 \mathrm{~W} \mathrm{~m}^{-2}$ and range is from -2.7 to $4.2 \mathrm{~W} \mathrm{~m}^{-2}$ during the period 2021-50; Fig. 5). Normalized by the change of $T_{a}$, the $E_{\text {pan }}$ [multimodel ensemble means of the projected $\left(d E_{\mathrm{pan}} / d t\right) /\left(d T_{a} / d t\right)$ during the periods $2021-50$ and $2071-$ 2100 relative to the baseline period 1971-2000] has been projected to increase at a rate of $117-167 \mathrm{~mm} \mathrm{yr}^{-1} \mathrm{~K}^{-1}$ (72-80 $\mathrm{mm} \mathrm{yr}^{-1} \mathrm{~K}^{-1}$ ) over China under the RCP 4.5 (RCP 8.5) scenario. Moreover, averaged over all sites, the multimodel ensemble means of seasonal $E_{\mathrm{pan}}$ would all increase especially for the period 2071-2100 (Fig. 6).

In terms of the spatial distribution, the increase in air temperature is uniform over all of China for both future periods and both emission scenarios, except for the relatively smaller increases at stations in southwestern China (Fig. 7). It is consistent with the projected results
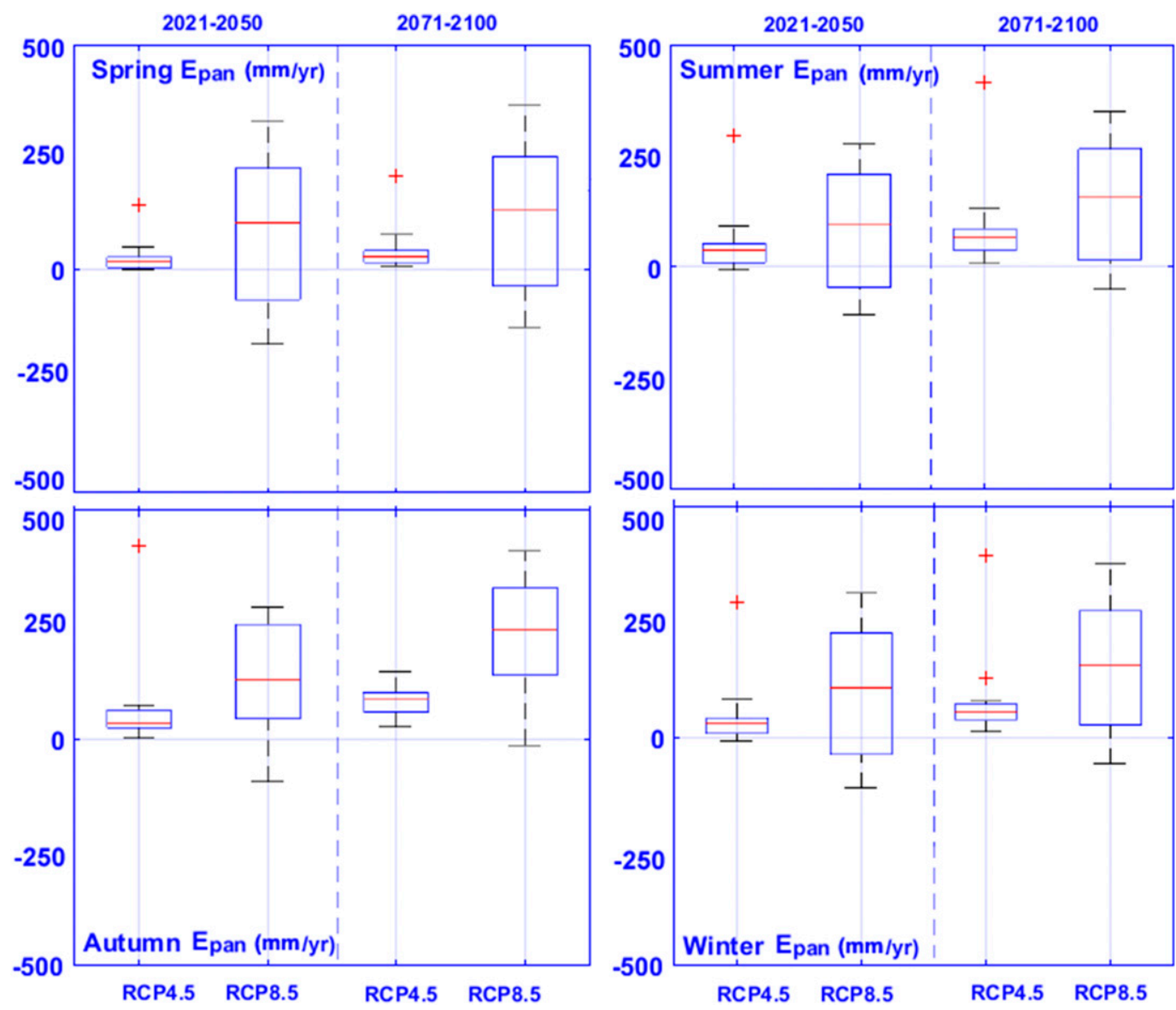

FIG. 6. As in Fig. 5, but for multisite-averaged seasonal $E_{\text {pan }}$. 


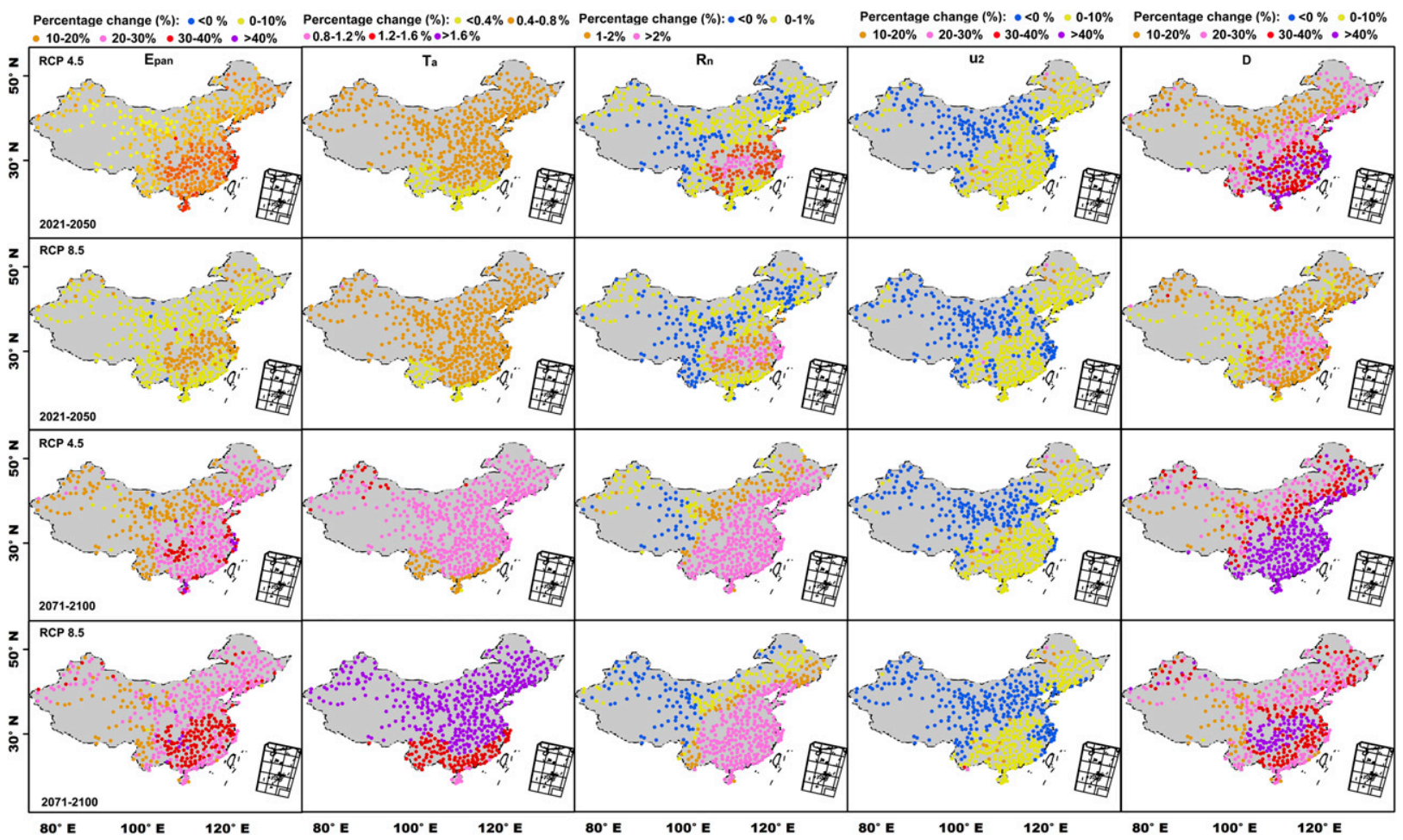

FIG. 7. Percentage changes (\%) of annual $E_{\mathrm{pan}}, T_{a}, R_{n}, u_{2}$, and $D$ at 534 stations over China during the periods 2021-50 and 2071-2100 relative to that during the baseline period 1971-2000, projected through ensemble means of multiple climate models under the RCP 4.5 and RCP 8.5 scenarios.

of future air temperature over China by $\mathrm{Xu}$ and $\mathrm{Xu}$ (2012) as well as Wang and Chen (2014) based on multiple CMIP5 GCMs. Moreover, there are regional differences for the increase of annual and seasonal $E_{\mathrm{pan}}$ as well as annual $D$ (Fig. 8), with relatively larger percentage changes in eastern China (especially in southeastern China) than in western China (e.g., Cook et al. 2014). The spatial pattern of $E_{\text {pan }}$ increase during the period 2021-50 is similar to that projected by Yin et al. (2015), which indicated that the reference evaporation increase is relatively less in western China than eastern China during the period 2041-73 relative to 1981-2010 under the RCP 4.5 and RCP 8.5 scenarios. The multimodel ensemble means of annual $R_{n}$ and $u_{2}$ exhibit distinct change patterns between eastern China (increase) and western China (decrease) for both periods and both emission scenarios. The spatial pattern for the percentage change of annual $u_{2}$ is quite similar to that projected by Chen et al. (2012).

\section{c. Attributing the future changes of $E_{\mathrm{pan}}$ over China}

Overall, the projected increase of annual $E_{\text {pan }}$ over China is attributed more to the annual $T_{a}$ and $D$ relative to annual $R_{n}$ and $u_{2}$ for both future periods and both emission scenarios (Fig. 9). For example, during the period 2021-50, the contributions of annual $T_{a}$ and $D$ to the increase of annual $E_{\text {pan }}$ (relative to the baseline period 1971-2010, median is $123 \mathrm{~mm} \mathrm{yr}^{-1}$ and range is $12-$ $310 \mathrm{~mm} \mathrm{yr}^{-1}$ ) are $80 \mathrm{~mm} \mathrm{yr}^{-1}$ (range is $48-138 \mathrm{~mm} \mathrm{yr}^{-1}$ ) and $64 \mathrm{~mm} \mathrm{yr}^{-1}$ (range is $2.4-201 \mathrm{~mm} \mathrm{yr}^{-1}$ ) while that of annual $R_{n}$ and $u_{2}$ are $7 \mathrm{~mm} \mathrm{yr}^{-1}$ (range is from -10 to $13 \mathrm{~mm} \mathrm{yr}^{-1}$ ) and $2 \mathrm{~mm} \mathrm{yr}^{-1}$ (range is $10-32 \mathrm{~mm} \mathrm{yr}^{-1}$ ) under the RCP 4.5 scenario. Both radiative and aerodynamic drivers of $E_{\text {pan }}$ would be enhanced under a warming climate. The results are consistent with many studies that related atmospheric evaporative demand (e.g., Wang et al. 2012) and drought (e.g., Dai 2011, 2013; Sheffield et al. 2012; Vicente-Serrano et al. 2014) to global warming. Although recent evidence has shown that the altering intensity of the global hydrological cycle is more relevant to the solar forcing rather than their thermal counterparts (e.g., Wild et al. 1998; Wild and Liepert 2010; Storelvmo et al. 2016), we did not find the significant contribution of enhanced net radiation to the increase of future $E_{\mathrm{pan}}$ over China under both emission scenarios in climate models. It is properly induced by the contrasting changes of net radiation in eastern and western China as well as the unrealistic aerosol forcing in climate models, which need to be further investigated in our future works. 


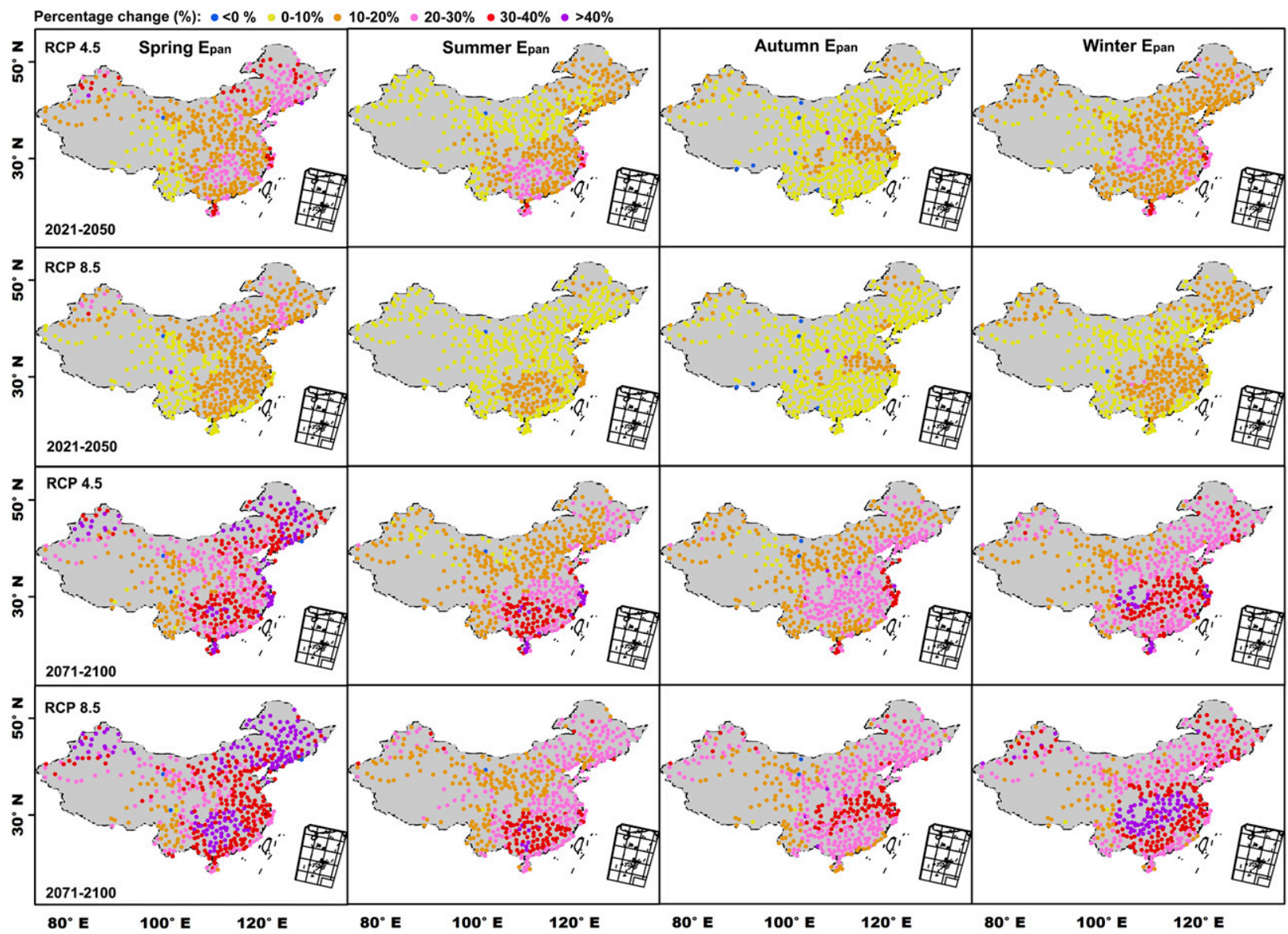

FIG. 8. As in Fig. 7, but for seasonal $E_{\text {pan }}$ [spring (March-May), summer (June-August), autumn (September-November), and winter (December-February)].

Liu et al. (2011) indicated that the annual $E_{\text {pan }}$ over China decreased by $-5.4 \mathrm{~mm} \mathrm{yr}^{-1}$ during the period 1960-91, mainly due to the significant decreases in $u_{2}$ and solar radiation, which offset the effect of increased $T_{a}$. However, it increased by $7.9 \mathrm{~mm} \mathrm{yr}^{-1}$ from 1992 to 2007 because of the seriously increased $T_{a}$ and solar radiation (insignificantly at the 0.10 level). That is to say, the phenomenon of pan evaporation paradox did not exist over China from 1992. This study revealed that the widely reported pan evaporation paradox would no longer appear over China based on the projections from multiple climate models. Although precipitation was also projected to increase over China (e.g., $\mathrm{Xu}$ and $\mathrm{Xu}$ 2012; Wang and Chen 2014), the ascending $E_{\text {pan }}$ would enhance the drought risks tied to the increased greenhouse gases and the associated warming of the climate system (e.g., Dai 2011; Cook et al. 2014). Some evidence also showed that $E_{\text {pan }}$ (demand) increased relatively faster than precipitation (supply) in some regions, which would amplify the drought severity (e.g., Yin et al. 2015; Berg et al. 2016). On the other hand, the $E_{\text {pan }}$ projections will overstate the drying over vegetated surfaces by ignoring the effect of $\mathrm{CO}_{2}$ on surface resistance (e.g., Roderick et al. 2015; Milly and Dunne 2016; Swann et al. 2016), which is beyond the scope of this study but deserves to be investigated in our future works.

\section{d. Uncertainty}

The presented results may unavoidably be associated with several uncertainties. First of all, the EQM method used did not show overall good performance in correcting the biased GCM-estimated interannual variability and long-term trends (relative to the absolute value) for annual $T_{a}, R_{n}, u_{2}$, and $D$ (and thus the calculated $\left.E_{\mathrm{pan}}\right)$, which is also a big challenge for most biascorrection (statistical downscaling) methods (e.g., Fowler et al. 2007; Maraun et al. 2010). To consider the limitation of EQM-based bias correction, we thus only showed the absolute changes of $E_{\mathrm{pan}}, T_{a}, R_{n}, u_{2}$, and $D$ between two periods in this study. Moreover, we also projected the future changes of annual $E_{\mathrm{pan}}, T_{a}, R_{n}, u_{2}$, 

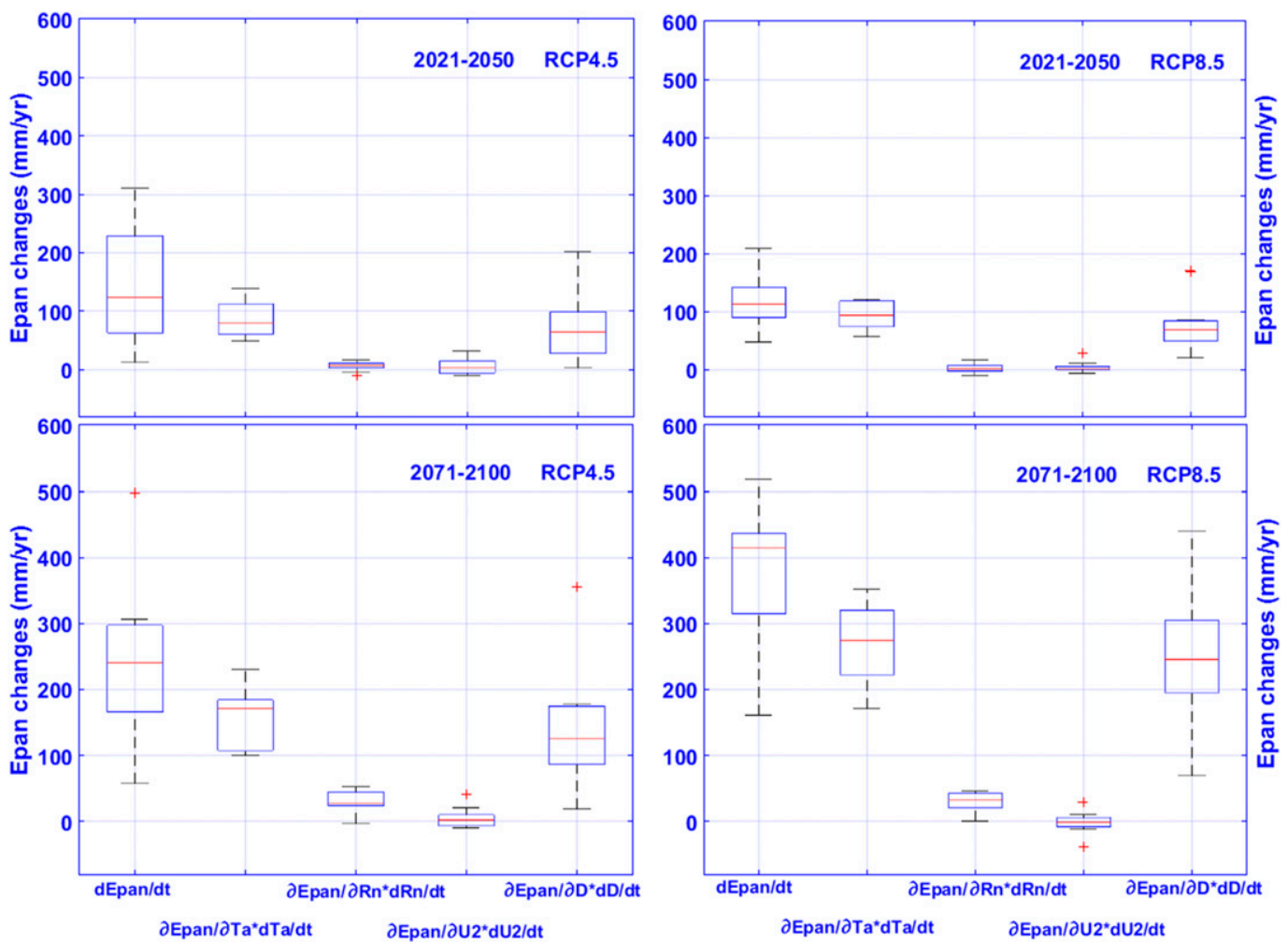

FIG. 9. Attribution of annual $E_{\mathrm{pan}}$ changes (mm) to $T_{a}, R_{n}, u_{2}$, and $D$ over China under RCP 4.5 and RCP 8.5 during the periods 2021-50 and 2071-2100, relative to that during the baseline period 1971-2000. The projected uncertainty of multiple climate models is shown through box plots for each variable and for each time period. The outliers are shown with red plus signs.

and $D$ at 534 stations over China using the original climate model outputs (please see Fig. S1 in the supplemental material). For example, averaged over all sites, the projected increase in the median of multimodel-estimated annual $E_{\mathrm{pan}}, T_{a}, R_{n}, u_{2}$, and $D$ are $95 \mathrm{~mm} \mathrm{yr}^{-1}$ (range is from -459 to $2204 \mathrm{~mm} \mathrm{yr}^{-1}$ ), $1.7^{\circ} \mathrm{C}$ (range is $0.6^{\circ}-2.5^{\circ} \mathrm{C}$ ), $1.0 \mathrm{~W} \mathrm{~m}^{-2}$ (range is from -1.1 to $2.1 \mathrm{~W} \mathrm{~m}^{-2}$ ), $0.002 \mathrm{~m} \mathrm{~s}^{-1}$ (range is from -3.15 to $0.17 \mathrm{~m} \mathrm{~s}^{-1}$ ), and $53 \mathrm{~Pa}$ (range is 9$1583 \mathrm{~Pa}$ ), respectively, for RCP 4.5 during the period 2021-50 relative to 1971-2000 (Fig. S1 in the supplemental material). Overall, the projected changes (e.g., the medians of multimodel ensemble means averaged over 534 stations) of annual $E_{\mathrm{pan}}, T_{a}, R_{n}, u_{2}$, and $D$ are similar to those calculated from the bias-corrected GCM outputs for each future period and emission scenario. However, the projected uncertainties among multiple climate models were obviously reduced, which can to some extent confirm the effectiveness of the EQM method.

Another source of uncertainty may arise from the calculation of regional mean by averaging the results directly at 534 meteorological sites, which has been widely used in hydrological and meteorological applications (e.g., Liu et al. 2004, 2011). We can interpolate the station-based results to surface first and then calculate the regional mean, but extra uncertainties would be introduced by various interpolation approaches (e.g., Erdin et al. 2012). The regional mean can also be calculated by averaging the GCM grid values after bias correction. However, only the GCM grid with observations over China can be bias corrected through the EQM method and be used for the calculation, which may inherit considerable uncertainties as well. Finally, several other improvements also need to be made in the PenPan model to further improve the simulation accuracy of $E_{\mathrm{pan}}$, for example, more accurate treatment of incoming and outgoing longwave radiation in evaporation pan and the calculation of the pan albedo (e.g., Rotstayn et al. 2006; Roderick et al. 2007; Liu and Sun 2016; Lim et al. 2016).

\section{Summary and conclusions}

In this study, the future changes (future periods 202150 and 2071-2100, relative to the baseline period 19712000) of $D_{20}$ pan evaporation (i.e., $E_{\mathrm{pan}}$ ) were first projected and attributed over China through the PenPan model forced by the latest suite of state-of-the-art climate model outputs under the RCP 4.5 and RCP 8.5 
scenarios. A bias-correction procedure (EQM) was first applied to reduce the systematic errors in multiple GCM outputs used in the PenPan model.

The EQM method showed acceptable performances for bias correcting $T_{a}, R_{n}, u_{2}$, and $D$ (and thus the calculated $\left.E_{\mathrm{pan}}\right)$ for all 534 meteorological stations over China during the period 1961-2000. However, the observed decline in $E_{\text {pan }}$ (e.g., during the period 1961-90) has still not been reasonably simulated by the multimodel ensemble mean of $E_{\text {pan }}$ calculated from the bias-corrected $T_{a}, R_{n}, u_{2}$, and $D$. Averaged over all sites, the annual and seasonal $E_{\mathrm{pan}}$ would increase during the periods 2021-50 and 2071-2100 relative to that in the baseline period 1971-2000 under RCP 4.5 and RCP 8.5, mainly due to the projected increase of air temperature and vapor pressure deficit under a warming climate. However, the percentage increase of $E_{\mathrm{pan}}$ in western China is a little bit less than that in eastern China, which is probably due to the spatially inconsistent increases of $T_{a}, R_{n}, u_{2}$, and $D$ over China. The pan evaporation paradox was not projected in climate models during two future periods and under two emission scenarios. The projected enhancement of $E_{\text {pan }}$ has important implications for drought that would challenge the water resources availability and agriculture production in China in the near future.

Acknowledgments. Wenbin Liu and Fubao Sun were financially supported by the National Key Research and Development Program of China (2016YFC0401401 and 2016YFA0602402). Fubao Sun was also supported by the Open Research Fund of State Key Laboratory of Desert and Oasis Ecology in Xinjiang Institute of Ecology and Geography, Chinese Academy of Sciences (CAS), the National Science Foundation of China (41330529), and CAS Pioneer Hundred Talents Program. Wenbin Liu was also supported by the National Science Foundation of China (41401037) and the Initial Founding of Scientific Research from the Institute of Geographic Sciences and Natural Resource Research, CAS (Y5V50019YE). We wish to thank the editors and two reviewers for their invaluable comments and constructive suggestions to improve the quality of the manuscript.

\section{APPENDIX}

\section{Formulation of the PenPan Model and Sensitivities to Its Forcing Variables}

\section{a. Estimation of the parameters in the PenPan model}

The $D$ in Eq. (3) can be calculated from $e_{s}$ and $e_{a}$, which can be formulated using the surface minimum air temperature $t_{\min }(\mathrm{K})$ and surface maximum air temperature $t_{\max }(\mathrm{K})$ as well as the relative humidity (rhum; \%; Liu and Sun 2016):

$$
\begin{aligned}
e_{s}= & \left\{610.8 \exp \left[\frac{17.27\left(t_{\max }-273.15\right)}{\left(t_{\max }-273.15\right)+237.3}\right]\right. \\
& \left.+610.8 \exp \left[\frac{17.27\left(t_{\min }-273.15\right)}{\left(t_{\min }-273.15\right)+237.3}\right]\right\} / 2
\end{aligned}
$$

and

$e_{a}=e_{s}($ rhum $)$.

The empirical vapor transfer function $f_{q}(u)\left(\mathrm{Kg} \mathrm{m}^{-2} \mathrm{~s}^{-1} \mathrm{~Pa}^{-1}\right)$ is a function of mean wind speed at $2 \mathrm{~m}$ above the ground $u_{2}\left(\mathrm{~m} \mathrm{~s}^{-1}\right)$ :

$$
f_{q}(u)=1.39 \times 10^{-8}\left(1+1.35 u_{2}\right)
$$

here the $u_{2}$ can be calculated through the wind speed at $10 \mathrm{~m}(z=10)$ above the ground $u_{10}\left(\mathrm{~m} \mathrm{~s}^{-1}\right)$ :

$$
u_{2}=u_{10} \frac{4.87}{\ln (67.8 z-5.42)}
$$

The $R_{n}$ in the PenPan model represents the net radiation $\left(\mathrm{W} \mathrm{m}^{-2}\right.$ ) of the pan:

$$
R_{n}=\left(1-A_{p}\right) R_{\mathrm{sp}}+R_{l_{\text {in }}}-R_{l_{\text {out }}},
$$

where $A_{p}$ is the pan albedo ( 0.14 in this study); $R_{\mathrm{sp}}$ is the incoming shortwave radiation of a pan, which is greater than $R_{s}$ (global solar irradiance) because of the additional interception by the pan walls:

$$
R_{\mathrm{sp}}=\left[P_{\mathrm{rad}} f_{\mathrm{dir}}+2\left(1-f_{\mathrm{dir}}\right)+2 \alpha\right] R_{s},
$$

where $\alpha$ is the ground surface albedo ( 0.23 in this study); $P_{\text {rad }} \quad\left(P_{\text {rad }}=1.32+0.0004|\varphi|+0.00008|\varphi|^{2}\right.$, where $\varphi$ is the latitude with units of degrees) is to consider the additional direct radiation intercepted by the wall of $D_{20}$ pan; $f_{\text {dir }}$ is the fraction of direct radiation, which can be calculated based on the downward solar radiation at the surface $R_{s}\left(\mathrm{~W} \mathrm{~m}^{-2}\right)$ and the incident shortwave radiation at the top of the atmosphere $R_{o}\left(\mathrm{Wm}^{-2}\right)$ $\left(f_{\text {dir }}=-0.11+1.31 R_{s} / R_{o}\right)$. The outgoing longwave irradiance from the pan $R_{l_{\text {out }}}\left(\mathrm{W} \mathrm{m}^{-2}\right)$ can be estimated by assuming the pan is a blackbody radiating at temperature $T_{a}(\mathrm{~K})$. For simplicity, we assume the incoming longwave irradiance at the pan water surface $R_{l_{\text {in }}}\left(\mathrm{W} \mathrm{m}^{-2}\right)$ is the same as that at the ground when estimating the monthly $E_{\text {pan }}$ with the GCM outputs. We thus directly used the GCM-outputted surface downwelling longwave flux, surface downwelling shortwave flux, and incident shortwave radiation at the top of the atmosphere as the $R_{l_{\text {in }}}, R_{s}$, and $R_{o}$ in this study. When 
estimating the $R_{n}$ using the meteorological data, we calculated the $R_{s}$ and $R_{o}$ based on the observed sunshine duration, latitude, and Julian days (with the parameters $a_{s}=0.25$ and $b_{s}=0.50$ ) and then calculated the $R_{l_{\text {in }}}$ using the Food and Agriculture Organization of the United Nations (FAO) 56 approach,

$$
\begin{aligned}
R_{l_{\mathrm{in}}}= & \sigma T_{a}^{4}\left\{1-\left(0.34-0.14 \sqrt{\frac{e_{a}}{1000}}\right)\right. \\
& \left.\times\left[\frac{1.35 R_{s}}{R_{o}\left(0.75+2 \times 10^{-5} z\right)}-0.35\right]\right\} ;
\end{aligned}
$$

here, $z$ is the station elevation $(\mathrm{m})$ and $\sigma$ is the StefanBoltzmann constant $\left(5.67 \times 10^{-8} \mathrm{~W} \mathrm{~m}^{-2} \mathrm{day}^{-1} \mathrm{~K}^{-4}\right)$.

\section{b. Attribution of the change in $E_{\mathrm{pan}}$}

The terms $\partial E_{\mathrm{pan}} / \partial T_{a}, \partial E_{\mathrm{pan}} / \partial u_{2}, \partial E_{\mathrm{pan}} / \partial D$, and $\partial E_{\mathrm{pan}} / \partial R_{n}$ in Eq. (4) could be detailed expanded as follows [Liu and Sun 2016; note that the $e$ in Eq. (A11) refers to exponential]:

$$
\begin{aligned}
& \frac{\partial E_{\mathrm{pan}}}{\partial u_{2}}=\frac{1.8765 \times 10^{-8} a \gamma D}{\Delta+a \gamma}, \\
& \frac{\partial E_{\mathrm{pan}}}{\partial D}=\frac{1.39 \times 10^{-8} a \gamma\left(1+1.35 u_{2}\right)}{\Delta+a \gamma}, \\
& \frac{\partial E_{\mathrm{pan}}}{\partial R_{n}}=\frac{\Delta}{\lambda(\Delta+a \gamma)}, \text { and }
\end{aligned}
$$

$$
\begin{aligned}
\frac{\partial E_{\mathrm{pan}}}{\partial T_{a}}= & \frac{(2503058) a \gamma R_{n}\left[3623.571-2\left(T_{a}-273.15\right)\right] e^{17.27\left(T_{a}-273.15\right) /\left(T_{a}-273.15\right)+237.3}}{\left[237.3+\left(T_{a}-273.15\right)\right]^{4}}-\frac{1.39 \times 10^{-8} a \gamma D\left(1+1.35 u_{2}\right)}{(\Delta+a \gamma)^{2}} \\
& +\frac{1.39 \times 10^{-8} a \gamma \times 610.8 \times 17.27 \times 237.3(1-\mathrm{rhum})\left(1+1.35 u_{2}\right) e^{17.27\left(T_{a}-273.15\right) /\left(T_{a}-273.15\right)+237.3}}{(\Delta+a \gamma)\left[237.3+\left(T_{a}-273.15\right)\right]^{2}} .
\end{aligned}
$$

\section{REFERENCES}

Azorin-Molina, C., and Coauthors, 2015: Atmospheric evaporative demand observations, estimates and driving factors in Spain (1961-2011). J. Hydrol., 523, 262-277, doi:10.1016/ j.jhydrol.2015.01.046.

Berg, A., and Coauthors, 2016: Land-atmosphere feedbacks amplify aridity increase over land under global warming. Nat. Climate Change, 6, 869-874, doi:10.1038/nclimate3029.

Brutsaert, W., and M. B. Parlange, 1998: Hydrologic cycle explains the evaporation paradox. Nature, 396, 30, doi:10.1038/23845.

Burn, D. H., and N. M. Hesch, 2007: Trends in evaporation for the Canadian Prairies. J. Hydrol., 336, 61-73, doi:10.1016/ j.jhydrol.2006.12.011.

Chen, D. L., G. Gao, C.-Y. Xu, J. Guo, and G. Ren, 2005: Comparison of the Thornthwaite method and pan data with the standard Penman-Monteith estimates of reference evapotranspiration in China. Climate Res., 28, 123-132, doi:10.3354/ cr028123.

Chen, L., S. C. Pryor, and D. L. Li, 2012: Assessing the performance of Intergovernmental Panel on Climate Change AR5 climate models in simulating and projecting wind speeds over China. J. Geophys. Res., 117, D24102, doi:10.1029/2012JD017533.

Cook, B. I., J. E. Smerdon, R. Seager, and S. Coats, 2014: Global warming and 21st century drying. Climate Dyn., 43, 2607-2627, doi:10.1007/s00382-014-2075-y.

Dai, A., 2006: Recent climatology, variability, and trends in global surface humidity. J. Climate, 19, 3589-3606, doi:10.1175/ JCLI3816.1.

— , 2011: Drought under global warming: A review. Wiley Interdiscip. Rev.: Climate Change, 2, 45-65, doi:10.1002/wcc.81. , 2013: Increasing drought under global warming in observations and models. Nat. Climate Change, 3, 52-58, doi:10.1038/ nclimate1633.
Erdin, R., C. Frei, and H. R. Künsch, 2012: Data transformation and uncertainty in geostatistical combination of radar and rain gauges. J. Hydrometeor., 13, 1332-1346, doi:10.1175/JHM-D-11-096.1.

Fowler, H. J., S. Blenkinsop, and C. Tebaldi, 2007: Linking climate change modeling to impacts studies: Recent advances in downscaling techniques for hydrological modeling. Int. J. Climatol., 27, 1547-1578, doi:10.1002/joc.1556.

Fu, G., S. P. Charles, and J. Yu, 2009: A critical overview of pan evaporation trends over the last 50 years. Climatic Change, 97, 193-214, doi:10.1007/s10584-009-9579-1.

Groisman, P. Ya., R. W. Knight, T. R. Karl, D. R. Easterling, B. Sun, and J. Lawrimore, 2004: Contemporary changes of the hydrological cycle over the contiguous United States: Trends derived from in situ observations. J. Hydrometeor., 5, 64-85, doi:10.1175/1525-7541(2004)005<0064:CCOTHC >2.0.CO;2.

Hobbins, M., J. Ramirez, and T. Brown, 2004: Trends in pan evaporation and actual evapotranspiration across the conterminous U.S.: Paradoxical or complementary? Geophys. Res. Lett., 31, L13503, doi:10.1029/2004GL019846.

, A. Wood, D. Streubel, and K. Werner, 2012: What drives the variability of evaporative demand across the conterminous United States? J. Hydrometeor., 13, 1195-1214, doi:10.1175/ JHM-D-11-0101.1.

Li, H., J. Sheffield, and E. F. Wood, 2010: Bias correction of monthly precipitation and temperature fields from Intergovernmental Panel on Climate Change AR4 models using equidistant quantile matching. J. Geophys. Res., 115, D10101, doi:10.1029/2009JD012882.

Li, Z., Y. N. Chen, Y. J. Shen, Y. B. Liu, and S. H. Zhang, 2013: Analysis of changing pan evaporation in the arid region of northwest China. Water Resour. Res., 49, 2205-2212, doi:10.1002/ wrcr.20202.

Liepert, B. G., J. Feichter, U. Lohmann, and E. Roeckner, 2004: Can aerosols spin down the water cycle in a warmer and 
moister world? Geophys. Res. Lett., 31, L06207, doi:10.1029/ 2003GL019060.

Lim, W. H., M. L. Roderick, M. T. Hobbins, S. C. Wong, and G. D. Farquhar, 2013: The energy balance of a US Class A evaporation pan. Agric. For. Meteor., 182-183, 314-331, doi:10.1016/ j.agrformet.2013.07.001.

,$- \ldots$, and G. D. Farquhar, 2016: A mathematical model of pan evaporation under steady state conditions. J. Hydrol., 540, 641-658, doi:10.1016/j.jhydrol.2016.06.048.

Linacre, E. T., 1994: Estimating U.S. Class A pan evaporation from few climate data. Water Int., 19, 5-14, doi:10.1080/ 02508069408686189.

Liu, B. H., M. Xu, M. Henderson, and W. G. Gong, 2004: A spatial analysis of pan evaporation trends in China, 1955-2000. J. Geophys. Res., 109, D15102, doi:10.1029/2004JD004511.

Liu, W. B., and F. B. Sun, 2016: Assessing estimates of evaporative demand in climate models using observed pan evaporation over China. J. Geophys. Res. Atmos., 121, 8329-8349, doi:10.1002/2016JD025166.

— G. B. Fu, C. M. Liu, X. Y. Song, and R. L. Ouyang, 2013: Projection of future rainfall for the North China Plain using two statistical downscaling models and its hydrological implications. Stochastic Environ. Res. Risk Assess., 27, 17831797, doi:10.1007/s00477-013-0714-1.

_- A. J. Zhang, L. Wang, G. B. Fu, D. L. Chen, C. M. Liu, and T. J. Cai, 2015: Projecting streamflow in Tangwang River basin (China) using a rainfall generator and two hydrological models. Climate Res., 62, 79-97, doi:10.3354/cr01261.

Liu, X. M., Y. Z. Luo, D. Zhang, M. H. Zhang, and C. M. Liu, 2011: Recent changes in pan-evaporation dynamics in China. Geophys. Res. Lett., 38, L13404, doi:10.1029/2011GL047929.

Maraun, D., and Coauthors, 2010: Precipitation downscaling under climate change: Recent developments to bridge the gap between dynamical models and the end user. Rev. Geophys., 48, RG3003, doi:10.1029/2009RG000314.

Maurer, E. P., and H. G. Hidalgo, 2008: Utility of daily vs. monthly large-scale climate data: An intercomparison of two statistical downscaling methods. Hydrol. Earth Syst. Sci., 12, 551-563, doi:10.5194/hess-12-551-2008.

McVicar, T. R., and Coauthors, 2012: Global review and synthesis of trends in observed terrestrial near-surface wind speed: Implications for evaporation. J. Hydrol., 416-417, 182-205, doi:10.1016/j.jhydrol.2011.10.024.

Milly, P. C. D., and K. A. Dunne, 2016: Potential evapotranspiration and continental drying. Nat. Climate Change, 6, 946-949, doi:10.1038/nclimate3046.

—, J. Betancourt, M. Falkenmark, R. M. Hirsch, Z. W. Kundzewicz, D. P. Lettenmaier, and R. J. Stouffer, 2008: Stationarity is dead: Whither water management? Science, 319, 573-574, doi:10.1126/science.1151915.

Panofsky, H. A., and G. W. Brier, 1968: Some Application of Statistics to Meteorology. Pennsylvania State University Press, 224 pp.

Penman, H. L., 1948: Natural evaporation from open water, bare soil and grass. Proc. Roy. Soc. London, 193A, 120-145, doi:10.1098/rspa.1948.0037.

Peterson, T. C., V. S. Golubev, and P. Ya. Grosiman, 1995: Evaporation losing its strength. Nature, 377, 687-688, doi:10.1038/ $377687 \mathrm{~b} 0$.

Roderick, M. L., and G. D. Farquhar, 2002: The cause of decreased pan evaporation over the past 50 years. Science, 298, 14101411, doi:10.1126/science.1075390-a.
- , and - 2004: Changes in Australian pan evaporation from 1970 to 2002. Int. J. Climatol., 24, 1077-1090, doi:10.1002/ joc. 1061 .

— and - 2005: Changes in New Zealand pan evaporation since the 1970s. Int. J. Climatol., 25, 2031-2039, doi:10.1002/ joc. 1262.

_ L. D. Rotstayn, G. D. Farquha, and M. T. Hobbins, 2007: On the attribution of changing pan evaporation. Geophys. Res. Lett., 34, L17403, doi:10.1029/2007GL031166.

— M. T. Hobbins, and G. D. Farquhar, 2009a: Pan evaporation trends and the terrestrial water balance. I. Principles and observations. Geogr. Compass, 3, 746-760, doi:10.1111/ j.1749-8198.2008.00213.x.

$\ldots, \ldots$, and — $2009 \mathrm{~b}$ : Pan evaporation trends and the terrestrial water balance. II. Energy balance and interpretation. Geogr. Compass, 3, 761-780, doi:10.1111/ j.1749-8198.2008.00214.x.

— P. Greve, and G. D. Farquhar, 2015: On the assessment of aridity with changes in atmospheric $\mathrm{CO}_{2}$. Water Resour. Res., 51, 5450-5463, doi:10.1002/2015WR017031.

Rotstayn, L. D., M. L. Roderick, and G. D. Farquhar, 2006: A simple pan-evaporation model for analysis of climate simulations: Evaluation over Australia. Geophys. Res. Lett., 33, L17715, doi:10.1029/2006GL027114.

Sachindra, D. A., F. Huang, A. Barton, and B. J. C. Perera, 2014: Statistical downscaling of general circulation model outputs to precipitation-part 2: Bias-correction and future projections. Int. J. Climatol., 34, 3282-3303, doi:10.1002/joc.3915.

Sheffield, J., E. F. Wood, and M. L. Roderick, 2012: Little change in global drought over the past 60 years. Nature, 491, 435-438, doi:10.1038/nature11575.

Shen, Y. J., and Coauthors, 2002: Measurement and analysis of evapotranspiration and surface conductance of a wheat canopy. Hydrol. Processes, 16, 2173-2187, doi:10.1002/hyp.1149.

Srivastav, R. K., A. Schardong, and S. P. Simonovic, 2014: Equidistance quantile matching method for updating IDF curves under climate change. Water Resour. Manage., 28, 2539-2562, doi:10.1007/s11269-014-0626-y.

Stanhill, G., and M. Möller, 2008: Evaporative climate change in the British Isles. Int. J. Climatol., 28, 1127-1137, doi:10.1002/ joc.1619.

Storelvmo, T., T. Leirvik, U. Lohmann, P. C. B. Phillips, and M. Wild, 2016: Disentangling greenhouse warming and aerosol cooling to reveal Earth's climate sensitivity. Nat. Geosci., 9, 286-289, doi:10.1038/ngeo2670.

Swann, A. L. S., F. M. Hoffman, C. D. Koven, and J. T. Randerson, 2016: Plant responses to increasing $\mathrm{CO}_{2}$ reduce estimates of climate impacts on drought severity. Proc. Natl. Acad. Sci. USA, 113, 10 019-10 024, doi:10.1073/pnas.1604581113.

Tebakari, T. J., J. Yoshitani, and C. Suvanpimol, 2005: Timespace trend analysis in pan evaporation over Kingdom of Thailand. J. Hydrol. Eng., 10, 205-215, doi:10.1061/ (ASCE)1084-0699(2005)10:3(205).

Thom, A. S., J. L. Thony, and M. Vauclin, 1981: On the proper employment of evaporation pans and atmometers in estimating potential transpiration. Quart. J. Roy. Meteor. Soc., 107, 711-736, doi:10.1002/qj.49710745316.

Van Schaeybroeck, B., and S. Vannitsem, 2016: Assessment of calibration assumptions under strong climate changes. Geophys. Res. Lett., 43, 1314-1322, doi:10.1002/2016GL067721.

Vautard, R., and Coauthors, 2014: The European climate under a $2^{\circ} \mathrm{C}$ global warming. Environ. Res. Lett., 9, 034006, doi:10.1088/1748-9326/9/3/034006. 
Vicente-Serrano, S. M., and Coauthors, 2014: Evidence of increasing drought severity caused by temperature rise in southern Europe. Environ. Res. Lett., 9, 044001, doi:10.1088/ 1748-9326/9/4/044001

Wang, J., Q. Wang, Y. Zhao, H. Li, J. Zhai, and Y. Shang, 2015: Temporal and spatial characteristics of pan evaporation trends and their attribution to meteorological drivers in the ThreeRiver Source Region, China. J. Geophys. Res. Atmos., 120, 6391-6408, doi:10.1002/2014JD022874.

Wang, K. C., R. E. Dickinson, and S. L. Liang, 2012: Global atmospheric evaporative demand over land from 1973-2008. J. Climate, 25, 8353-8361, doi:10.1175/JCLI-D-11-00492.1.

Wang, L., and W. Chen, 2014: A CMIP5 multimodel projection of future temperature, precipitation, and climatological drought in China. Int. J. Climatol., 34, 2059-2078, doi:10.1002/joc.3822.

Wang, W. G., and Coauthors, 2013: Changes in reference evapotranspiration across the Tibetan Plateau: Observations and future projections based on statistical downscaling. J. Geophys. Res. Atmos., 118, 4049-4068, doi:10.1002/jgrd.50393.

Wilcke, R. A. I., T. Mendlik, and A. Gobiet, 2013: Multi-variable error correction of regional climate models. Climatic Change, 120, 871-887, doi:10.1007/s10584-013-0845-x.

Wild, M., and B. Liepert, 2010: The earth radiation balance as driver of the global hydrological cycle. Environ. Res. Lett., 5 , 025203, doi:10.1088/1748-9326/5/2/025203.
A. Ohmura, H. Gilgen, E. Roeckner, M. Giorgetta, and J.-J. Morcrette, 1998: The disposition of radiative energy in the global climate system: GCM-calculated versus observational estimates. Climate Dyn., 14, 853-869, doi:10.1007/s003820050260.

Wilks, D. S., 2012: Stochastic weather generators for climatechange downscaling, part II: Multivariable and spatially coherent multisite downscaling. Wiley Interdiscip. Rev.: Climate Change, 3, 267-278, doi:10.1002/wcc.167.

$\mathrm{Xu}, \mathrm{C} . \mathrm{H}$., and Y. Xu, 2012: The projection of temperature and precipitation over China under RCP scenarios using a CMIP5 multi-model ensemble. Atmos. Ocean. Sci. Lett., 5 (6), 427-433.

Xu, Y. P., S. L. Pan, G. T. Fu, Y. Tian, and X. J. Zhang, 2014: Future potential evapotranspiration changes and contribution analysis in Zhejiang Province, east China. J. Geophys. Res. Atmos., 118, 2174-2196, doi:10.1002/2013JD021245.

Ye, B., D. Yang, and J. Li, 2012: Effect of precipitation bias correction on water budget calculation in Upper Yellow River, China. Environ. Res. Lett., 7, 02520, doi:10.1088/1748-9326/7/2/025201.

Yin, Y. H., D. Y. Ma, S. H. Wu, and T. Pan, 2015: Projections of aridity and its regional variability over China in the mid-21st century. Int. J. Climatol., 35, 4387-4398, doi:10.1002/joc.4295.

Zhang, Y., C. Liu, Y. Tang, and Y. Yang, 2007: Trends in pan evaporation and reference and actual evapotranspiration across the Tibetan plateau. J. Geophys. Res., 112, D12110, doi:10.1029/2006JD008161. 